\title{
No more Mr Nice Guy - implementation of mandatory seasonal influenza immunization for all personnel
}

\author{
JP Parada ${ }^{1 *}$, M Koller $^{1}$, J Carlson-Steinmetz ${ }^{2}$, B Gaughan² , C Schleffendorf ${ }^{2}$, M Capelli-Schellpfeffer ${ }^{1}$, P Hindle ${ }^{2}$ \\ From International Conference on Prevention \& Infection Control (ICPIC 2011) \\ Geneva, Switzerland. 29 June - 2 July 2011
}

\section{Introduction / objectives}

In the US, immunization for many vaccine preventable illnesses are mandated as a condition of employment, but Influenza (flu) has not been mandatory. Despite 1986 Center for Disease Control recommendations that healthcare workers be vaccinated annually for flu, the US national average is $61.9 \%$. Patient \& employee safety / preventing nosocomial infections are central to quality care. So, we sought to achieve universal flu immunization for all personnel.

\section{Methods}

With firm commitment of leadership, seasonal flu immunization was mandated as condition of employment. A multidisciplinary task force guided interventions/policy changes. We launched an internal media blitz. Paper \& electronic tracking systems measured compliance. We developed a formal exemption process. Nursing administration \& pharmacy coordinated vaccination.

\section{Results}

Pre-mandatory immunization, our baseline 3-year flu vaccination rate was $65 \%$ (range $62-72 \%$ ). In the 2 years since mandatory flu immunization was instituted we achieved a $>99 \%$ immunization rate. In 2009, 7795/ 7854 (99.2\%) personnel received vaccine, $52(0.7 \%)$ were exempted for religious/medical reasons, and 9 employees $(0.1 \%)$ refused vaccination, choosing to terminate employment. In 2010, 8030/8091 (99.2\%) were vaccinated, $60(0.7 \%)$ were exempted, and 1 person $(0.01 \%)$ chose to terminate employment.

\section{Conclusion}

$100 \%$ participation in flu immunization in the healthcare setting is possible and near universal flu immunization is achievable and sustainable. It is doubtful that these levels of immunization would be achievable if not as a condition of employment. We believe that patient/ employee safety have been enhanced, and quality of care is improved.

\section{Disclosure of interest}

J. Parada Grant/Research support from Astellas, Roche, Speaker's Bureau of Optimer, Consultant for Merck, M. Koller: None Declared, J. Carlson-Steinmetz: None Declared, B. Gaughan: None declared, C. Schleffendorf: None declared, M. Capelli-Schellpfeffer: None declared, P. Hindle Consultant for Medline.

\section{Author details}

${ }^{1}$ Medicine, Loyola University, Maywood, IL, USA. ${ }^{2}$ Nursing, Loyola University, Maywood, IL, USA.

Published: 29 June 2011

doi:10.1186/1753-6561-5-S6-P276

Cite this article as: Parada et al:: No more Mr Nice Guy -

implementation of mandatory seasonal influenza immunization for all personnel. BMC Proceedings 2011 5(Suppl 6):P276.

${ }^{1}$ Medicine, Loyola University, Maywood, IL, USA

Full list of author information is available at the end of the article

(C) 2011 Parada et al; licensee BioMed Central Ltd. This is an open access article distributed under the terms of the Creative Commons 